\title{
Does Cholecystectomy Increase the Esophageal Alkaline Reflux? Evaluation by Impedance-pH Technique
}

\author{
Ahmet Uyanikoglu, ${ }^{1 *}$ Filiz Akyuz, ${ }^{2}$ Fatih Ermis, ${ }^{2}$ Serpil Arici, ${ }^{2}$ Gurhan Bas, ${ }^{3}$ Mustafa Cakirca, ${ }^{4}$ Bulent Baran ${ }^{2}$ and Zeynel Mungan ${ }^{2}$ \\ ${ }^{1}$ Department of Gastroenterology, Harran University Faculty of Medicine, Sanliurfa, Turkey; ${ }^{2}$ Department of Gastroenterohepatology, Istanbul \\ Faculty of Medicine, Istanbul University, Istanbul, Turkey; ${ }^{3}$ Department of General Surgery, Vakif Gureba Training and Research Hospital, \\ Istanbul, Turkey; and ${ }^{4}$ Department of Internal Medicine, Vakif Gureba Training and Research Hospital, Istanbul, Turkey
}

\section{Background/Aims}

The aim of this study is to investigate the reflux patterns in patients with galbladder stone and the change of reflux patterns after cholecystectomy in such patients.

\section{Methods}

Fourteen patients with cholecystolithiasis and a control group including 10 healthy control subjects were enrolled in this prospective study. Demographical findings, reflux symptom score scale and 24-hour impedance pH values of the 14 cholecystolithiasis cases and the control group were evaluated. The impedance $\mathrm{pH}$ study was repeated 3 months after cholecystectomy.

\section{Results}

Age, gender, and BMI were not different between the two groups. Total and supine weakly alkaline reflux time (\%) (1.0 vs $22.5, P=0.028 ; 201.85$ vs $9.65, P=0.012)$, the longest episodes of total, upright and supine weakly alkaline reflux mediums ( 11 vs $2, P=0.025 ; 8.5$ vs $1.0, P=0.035 ; 3$ vs $0, P=0.027$ ), total and supine weakly alkaline reflux time in minutes ( 287.35 vs $75.10, P=0.022 ; 62.5$ vs $1.4, P=0.017$ ), the number of alkaline reflux episodes ( 162.5 vs $72.5, P=0.022$ ) were decreased with statistical significance. No statistically significant difference was found in the comparison of symptoms between the subjects in the control group and the patients with cholecystolithiasis, in preoperative, postoperative and postcholecystectomy status.

\section{Conclusions}

Significant reflux symptoms did not occur after cholecystectomy. Post cholecystectomy weakly alkaline reflux was decreased, but it was determined that acid reflux increased after cholecystectomy by impedance $\mathrm{pH}$-metry in the study group.

(J Neurogastroenterol Motil 2012;18:187-193)

\section{Key Words}

Cholecystectomy; Cholecystolithiasis; Gastroesophageal reflux; Impedance pH

Received: October 3, 2011 Revised: January 24, 2012 Accepted: February 1, 2012

(c) This is an Open Access article distributed under the terms of the Creative Commons Attribution Non-Commercial License (http://creativecommons. org/licenses/by-nc/3.0) which permits unrestricted non-commercial use, distribution, and reproduction in any medium, provided the original work is properly cited.

*Correspondence: Ahmet Uyanikoglu, MD Department of Gastroenterology, Harran University Faculty of Medicine, Sanliurfa 63300, Turkey Tel: +90-542-345-5513, Fax: +90-414-315-1181, E-mail: auyanikoglu@hotmail.com

Financial support: Esophageal impedance $\mathrm{pH}$-metry catheters used in this study were invested by Istanbul University and supported by Rectorate Scientific Research Unit (Project No. 2179).

Conflicts of interest: None. 


\section{Introduction}

The treatment of symptomatic cholecystolithiasis is cholecystectomy. ${ }^{1}$ Laparoscopic cholecystectomy is usually applied. Postcholecystectomy syndrome may occur after cholecystectomy. Postcholecystectomy syndrome is a heterogeneous condition and may occur depending on many causes. One of the suggested reasons is the increase in gastroesophageal reflux diseases. ${ }^{2-4}$

Relationship between the gallbladder stone and the reflux; whether reflux increases after cholecystectomy is a controversial subject. ${ }^{5,6}$ In current studies, assessments of reflux were performed by different techniques such as interview, endoscopy and 24-hour $\mathrm{pH}$ monitoring. These evaluations are often useful in detecting acid reflux, ${ }^{6-8}$ whereas it is known that alkaline bile reflux may be detectable in stomach after cholecystectomy. ${ }^{9-11}$ Determination of bile reflux in esophagus after cholecystectomy is possible and informative. This situation may be important, because the alkaline reflux is accepted as a contributing factor for Barrett's esophagus. ${ }^{12}$

Bile reflux into the stomach is reported in a rate of $30 \%-100 \%$ after stomach surgery and $80 \%-90 \%$ after gallbladder surgery. ${ }^{9-11,13}$ Even though bile reflux to stomach occurs frequently, it does not always damage the gastric and esophageal mucosa. Leaking up into the stomach (reflux), the bile and pancreatic secretions present in the duodenum content mix up with the hydrochloric acid and pepsin present in stomach, and thereby damage occurs in the gastric and esophageal mucosa. The continuation of this interaction may develop gastritis and esophagitis. ${ }^{14}$ Recently developed esophageal impedance-pH is used to monitor all kinds of reflux episodes (acid, weakly acid and weakly alkaline), components of refluxate (gas, liquid and mixed), proximal extend of refluxate and esophageal clearance. ${ }^{15-17}$

The aim of this study is to investigate the relationships between gastroesophageal reflux, cholecystolithiasis and cholecystectomy using the impedance $\mathrm{pH}$ method.

\section{Materials and Methods}

\section{Subject}

Fourteen patients, who were planned with open or laparoscopic cholecystectomy due to gallbladder stones and 10 healthy volunteers were prospectively enrolled. Those subjects who had a history of (a) previous stomach or esophageal surgeries, malig- nancies, gastrointestinal disorders other than gastroesophageal reflux diseases or gallbladder stones were excluded from this study. Ultrasonographic gallbladder and liver examinations were carried out among the participants in the control group. The participants who had gallbladder stones and bile duct dilatations were excluded from the control group.

\section{Study Design}

At the onset of the study, the participants underwent physical examinations. Medical histories, family histories, social habits (alcohol use and smoking) and body mass index (BMI) scores were evaluated. Subsequently, participants were evaluated with the 24-hour esophageal impedance-pH meter through a similar approach.

Information regarding the study was provided to the patients and the healthy volunteers in the control group and their written informed consents were taken in accordance with the Helsinki Declaration. Height, weight and BMI scores (BMI: weight $[\mathrm{kg}] /$ height $\left[\mathrm{m}^{2}\right]$ ) were calculated. Symptom's scale was applied to the patients before the operation and also at the third month after the operation.

Patients were evaluated with the 24-hour esophageal impedance-pH meter without disrupting their daily routine activities. Catheters were removed at 8:00 am the next morning after their insertions. Three months after the surgery, all patients were reassessed with the symptom's scale. Esophageal impedance-pH meter was applied once again to all (of) patients with the same method. Symptom's scale and the impedance-pH meter results were compared among the patients in the preoperative and postoperative period as well as with the control group.

\section{Twenty-four Hour Ambulatory Esophageal Impedance-pH Metry}

Ambulatory 24 hours esophageal impedance-pH metry was performed with a mobile recording device (Ohmega Impedanceambulatory $\mathrm{pH}$ meter; MMS, Enschede, Netherlands) and the catheter had 8 impedance ring and 1 antimony $\mathrm{pH}$ measurement loop (Versa Flex Z-Impedance $\mathrm{pH}$ metry disposable catheters; Alpine bio Med, Fountain Valley, CA, USA). Impedance-pH metry catheters were passed transnasally under topical anaesthesia and positioned to record $\mathrm{pH} 5$ and impedance at 3, 5, 7, 9, 15 and $17 \mathrm{~cm}$ proximal to lower esophageal sphincter (LES) in the esophageal body at 8:00 am. Gastroscopy was performed and LES was determined. Postero-anterior chest X-ray graphy was taken. Catheter was not removed until the following day at 8:00 
am. After a 24-hour investigation, recordings were uploaded onto a personal computer. All data were interpreted under a related program manually by an expert. Gastroesophageal reflux was defined as a sequential orally progressing drop in impedance to less than $50 \%$ of baseline values starting distally $(3 \mathrm{~cm}$ above the LES) and propagating retrogradely to at least the next 2 more proximal impedance rings. According to the corresponding $\mathrm{pH}$ change, impedance detected reflux was classified as follows:

(1) Acid reflux: $\mathrm{pH}$ decrease below 4 for a period of at least 4 seconds during reflux or at least 1 unit decrease in $\mathrm{pH}$ for at least 4 seconds when $\mathrm{pH}$ is already below 4 (acid re-reflux) (superimposed reflux) were defined as acid reflux.

(2) Weakly acidic reflux: At least 1 unit of $\mathrm{pH}$ decrease for at least 4 seconds, while the maintenance of $\mathrm{pH}$ between 4-7 during the reflux were defined as weak acid reflux.

(3) Weakly alkaline (non-acid) reflux: $\mathrm{pH}$ above 7 during reflux was defined as weak alkaline reflux. ${ }^{18}$

Each reflux episode was classified as liquid, gas or mixed. Liquid, gas, mixed, acid, weak acid and weak alkaline reflux, the percentage of time period of $\mathrm{pH}<4$ relative to the total time, the number of episodes with $\mathrm{pH}<4$ were evaluated seperately for 24 hours recording period in the supine and standing positions.

The number and percentage of reflux episodes extending to the proximal (the number of reflux episodes extending $15 \mathrm{~cm}$ above the esophagus sphincter), bolus clearance time, the number of swallows and the DeMeester score were evaluated as a 24 hours record. ${ }^{19}$

\section{Symptom's Scale}

The preoperative and postoperative patients and also the control group were evaluated by scaled prepared before impedance.
The scores were set as follows: no symptoms $=0$, low $=1$, moderate $=2$ and high $=3{ }^{20}$ The mean symptom scores were compared.

\section{Statistical Methods}

Statistical analyses were carried out by SPSS 13.0. Independent groups were compared by the non-parametric Mann-Whitney $\mathrm{U}$ test. Dependent groups were evaluated with the Wilcoxon sign rank test. Correlation analyses were performed by the Spearman correlation tests. A $P$-value lower than 0.05 was considered to be statistically significant.

\section{Results}

Fourteen patients with cholecystolithiasis and 10 healthy controls were enrolled and the symptom scale and impedance-pH measurements were performed. For the reason that the surgery had been postponed in three patients and as one patient did not want to take the impedance-pH measurement test after surgery, only 10 patients' symptom scales were reevaluated postoperatively in the 3rd month as control impedance-pH measurements. Patients' symptoms scales during pre- and post-cholecystectomy and impedance results were compared with each other and with the control group.

The median age of 14 patients included in the study was 53.5 year, while $6(43 \%)$ were male and $8(57 \%)$ were women. BMI median average was $30.9 \mathrm{~kg} / \mathrm{m}^{2}$. In proportion to their BMIs, 5 patients were overweight $\left(25-30 \mathrm{~kg} / \mathrm{m}^{2}\right)$ and 9 patients were obese $\left(30-40 \mathrm{~kg} / \mathrm{m}^{2}\right)$. Five patients had co-morbidity: 2 patients with essential hypertension, 1 patient with diabetes mellitus, 1 patient with hypertension and ischemic heart disease, 1 patient with

Table 1. Demographic Characteristics of Patient and Control Groups

\begin{tabular}{|c|c|c|c|}
\hline & Patients $(n=14)$ & Controls $(n=10)$ & $P$-value \\
\hline Age (median [range], yr) & $53.5(28-74)$ & $44.5(32-54)$ & $>0.680$ \\
\hline Gender $(\mathrm{M} / \mathrm{F})$ & $6 / 8$ & $5 / 5$ & $>0.735$ \\
\hline BMI (median [range], $\mathrm{kg} / \mathrm{m}^{2}$ ) & $30.9(25.4-37.5)$ & $28.2(24.5-32.5)$ & $>0.570$ \\
\hline GB family history (n) & $4(29 \%)$ & $4(40 \%)$ & $>0.620$ \\
\hline Smoking (n) & 3 & 2 & $>0.934$ \\
\hline Alcohol (n) & 1 & 3 & $>1.610$ \\
\hline Co-morbidity (n) & & & $>0.701$ \\
\hline Diabetes mellitus & 1 & 1 & \\
\hline Hypertension & 2 & 1 & \\
\hline Ischemic heart disease & 2 & 1 & \\
\hline
\end{tabular}

BMI, body mass index; GB, gallbladder. 
diabetes mellitus and iscemic heart disease. Four patients had a family history of gallbladder stone (29\%). Three of the 14 patients $(21.4 \%)$ were smokers, 1 patient had alcohol abuse history (Table 1). One patient with choledocholithiasis underwent preoperative endoscopic retrograde cholangiopancreography, as well as sphincterotomy and stone extraction. One patient had biliary pancreatitis, 1 patient had liver hemangioma and 1 patient had an umbilical hernia.

Cholecystectomy was performed in eleven of the fourteen patients. Nine patients underwent laparoscopic cholecystectomy, 1 patient had laparoscopic cholecystectomy and umbilical hernia repair and in 1 patient the surgery started as a laparoscopic surgery, however, continued as an open surgery for technical reasons. The surgery was abandoned in three patients, because of the cardiac reasons in two of them and on his own request in one. Regarding the BMI of the patients group, 2 patients were overweight and 8 patients were obese. There were no normal weight or morbidly obese patients.

In the control group, the mean age of 10 subjects was 44.5 years and $5(50 \%)$ of them were male and $5(50 \%)$ were women. BMI median average was $28.2 \mathrm{~kg} / \mathrm{m}^{2}$. Regarding their BMI, 1 subject was normal weight, 7 subjects were overweight and 2 subjects were obese. There were no morbidly obese subjects. Seven people had no known disease. Three people had diabetes mellitus, hypertension, ischemic heart disease and dyslipidemia history respectively. None of the subjects in the control group showed gallbladder or bile duct dilatation, through ultrasound scan, but 3 patients $(30 \%)$ had steatosis. Four subjects (40\%) had a family history of gallbladder stone (2 mothers, 1 father and 1 brother). Two people in the control group were smokers (20\%) and 3
(30\%) had alcohol abuse history (Table 1).

There was no significant difference in terms of demographic data (age, gender distribution, BMI, habits, family history or accompanying diseases etc) in the patients with cholecystolithiasis, cholecystectomy and in the control group.

No statistical significance was found in the comparison of symptoms between the subjects in the control group and the patients with cholecystolithiasis. There were no significant differences obtained, when the preoperative and postoperative symptoms were compared. When symptoms in postcholecystectomy patients and the control group were compared, there was no statistical significant difference.

\section{Comparison of the Patients With Gallblad- der Stone Versus the Control Group}

When the impedance-pH metry results of the patients were compared with the results of control group, the total time of weakly alkaline reflux ( $\min )(P=0.056)$ and upright weakly alkaline reflux time $(\mathrm{min})(P=0.056)$ had increased but not in the limits of statistical significancy; the longest episode of weakly alkaline reflux $(P=0.031)$ and the longest episode of upright alkaline reflux $(P=0.019)$ were significantly greater in control group. Number of episodes with $\mathrm{pH}<4$ was significantly higher in control group $(P=0.048)$. However, other parameters did not differ in terms of acid reflux.

A correlation between patients with gallbladder stone presence and the number of alkaline reflux episodes and control group was determined ( $\mathrm{R}=0.747, P=0.001)$. With reference to the impedance results, it was determined that the gallbladder stones increased the alkaline reflux, although there was no corre-

Table 2. Changes of Esophageal Reflux Patterns After Cholecystectomy

\begin{tabular}{lccc}
\hline & Pre-cholecystectomy $^{\mathrm{a}}$ & Post-cholecystectomy $^{\mathrm{a}}$ & $P_{\text {-value }}{ }^{\mathrm{b}}$ \\
\hline Supine weakly alkaline reflux time & $201.85(1-161)$ & $69.65(0-193.8)$ & 0.012 \\
Longest episodes of total, weakly alkaline reflux mediums & $11(0-82)$ & $2(0-119)$ & 0.025 \\
Longest episodes of upright weakly alkaline reflux mediums & $8.5(0-39)$ & $1(0-9)$ & 0.035 \\
Longest episodes of supine weakly alkaline reflux mediums & $3(0-8)$ & $0(0-3)$ & 0.027 \\
Total weakly alkaline reflux time in minutes & $287.35(1-1360)$ & $75.1(0-284)$ & 0.022 \\
Supine weakly alkaline reflux time in minutes & $62.5(0-334.3)$ & $1.4(0-95.8)$ & 0.017 \\
The number of alkaline reflux episodes & $162.5(4-406)$ & $72.5(0-234)$ & 0.022 \\
The number of total gas reflux & $20.5(1-43)$ & $27(7-110)$ & 0.037 \\
The number of upright gas reflux & $18(1-42)$ & $22.5(5-72)$ & 0.028 \\
Time that pH $<4$ (\%) & $0.3(0-4.4)$ & $0.9(0.1-25.2)$ & 0.021 \\
Longest episodes of acid reflux & $0.85(0-6.6)$ & $1.80(0.5-43.4)$ & 0.080
\end{tabular}

${ }^{a}$ Median (range), ${ }^{b}$ Non-parametric Mann-Whitney U test. 
lation with the symptoms.

\section{Changes of Esophageal Reflux Patterns After Cholecystectomy}

Total and supine weakly alkaline reflux time (\%) (1.0 vs 22.5 , $P=0.028 ; 201.85$ vs $9.65, P=0.012)$, the longest episodes of total, upright and supine weakly alkaline reflux mediums (11 vs 2, $P=0.025 ; 8.5$ vs $1.0, P=0.035 ; 3$ vs $0, P=0.027)$, total and supine weakly alkaline reflux time in minutes $(287.35$ vs $75.1, P$ $=0.022 ; 62.5$ vs $1.4, P=0.017)$, the number of alkaline reflux episodes $(162.5$ vs $72.5, P=0.022)$ decreased with statistical significance (Table 2).

The number of total and upright gas reflux $(P=0.037$ and $P=0.028)$ and time of $\mathrm{pH}<4(\%)(P=0.021)$ increased wityh statistical significance in cholecystectomy patients compared to the results during pre-operative period. There was no significant difference in the comparison of the postoperative patients and control group's parameters (Table 2).

Even though the acid reflux increased after cholecystectomy, no statistical significance was detected in comparison with the control group. Although a decrease was determined in the postoperative alkaline reflux recordings, it showed no significant difference with the control group. In addition, the preoperative and postoperative average symptom scores presented no significant differences (Table 3 ).

Individual differences between the preoperative and postoperative number of episodes $\mathrm{pH}<4$ presented no significant difference. Even though there were differences in average De Meester scores, these were not statistically significant.

\section{Discussion}

Gallbladder stone is a common condition and cholecystectomy is frequent operation. ${ }^{1,17}$ As bile acid's duodenogastrical reflux increased after cholecystectomy it is thought that the alkaline reflux into the esophagus may also increase..$^{9-11}$ There are studies showing the reflux increase after cholecystectomy and also there are studies showing the contrary. ${ }^{5,6}$ Although reflux after cholecystectomy is well investigated, there are not many studies investigating the relationship between cholecystolithiasis and gastroesophageal reflux (GER). Classic pH-meters can detect only acid reflux, but the impedance-pH metry could monitor all kinds of reflux. For these reasons, the aim of this study is to investigate the relationship between cholecystolithiasis, cholecystectomy and GER through impedance-pH metry.
Table 3. Comparison of Symptom Severity Scores in Pre-cholecystectomy, Post-cholecystectomy Status and Control

\begin{tabular}{lccc}
\hline \multicolumn{1}{c}{ Symptoms } & $\begin{array}{c}\text { Pre- } \\
\text { cholecystectomy }{ }^{\mathrm{a}}\end{array}$ & $\begin{array}{c}\text { Post- } \\
\text { cholecystectomy }\end{array}{ }^{\mathrm{a}}$ Control $^{\mathrm{a}}$ \\
\hline Heartburn & $0(0-2)$ & $0(0-1)$ & $0(0-3)$ \\
Acid regurgitation & $0(0-2)$ & $0(0-1)$ & $0(0-2)$ \\
Food regurgitation & $0(0-3)$ & $0(0-1)$ & $0(0-2)$ \\
Chest pain & $0(0-2)$ & $0(0-1)$ & $0(0-1)$ \\
Dysphagia & $0(0-1)$ & $0(0-0)$ & $0(0-1)$ \\
Odynophagia & $0(0-1)$ & $0(0-0)$ & $0(0-0)$ \\
Nausea & $0(0-1)$ & $0(0-1)$ & $0(0-1)$ \\
Vomiting & $0(0-3)$ & $0(0-0)$ & $0(0-2)$ \\
Choking & $1(0-3)$ & $1(0-3)$ & $1(0-3)$ \\
Throat ache & $0(0-1)$ & $0(0-1)$ & $0(0-2)$ \\
Hoarseness & $1(0-3)$ & $1(0-2)$ & $1(0-3)$ \\
Night cough & $0(0-1)$ & $0(0-1)$ & $0(0-2)$ \\
Dyspnea & $0(0-1)$ & $0(0-0)$ & $0(0-1)$ \\
Wheezing & $0(0-1)$ & $0(0-0)$ & $0(0-0)$ \\
\hline
\end{tabular}

Values represented as a median (range). ${ }^{\mathrm{a}}$ Non-parametric Mann-Whitney $\mathrm{U}$ test $(P>0.05)$.

Mucosal pathology has been determined by endoscopy, in about half of the GER cases. ${ }^{21}$ Non-erosive reflux disease has been determined in $65 \%$ of the GER cases, in GORHEN multicentered study carried out in Turkey. ${ }^{22}$ As it is shown by these studies, the endoscopy and 24-hour pH-metry present low sensitivity in the diagnosis of GER. When the impedance technique is combined with pH-metry, it can measure the weakly acid and non acid reflux, thus it is seen as a promising method ${ }^{23}$ for the diagnosis of reflux diseases.

There are conflicting results among studies where reflux is evaluated with only questioning the symptoms. ${ }^{5,624,25}$ Esophageal reflux symptoms are determined among $40 \%$ of the post cholecystectomy patients, which is similar to the rates reported in the general population. In a study where the symptoms of 212 post laparoscopic cholecystectomy patients and 62 acalculous healthy controls were compared, the rates of abdominal pain, bloating and nausea did not differ significantly. Significant differences were determined for regurgitation (19.3 to $3.2, P=0.004$ ), whereas a borderline significance was detected for dysphagia (11.3 to $6.4, P=0.080$ ). As a result, it was concluded that esophageal reflux symptoms after laparoscopic cholecystectomy were more common compared to the control group. ${ }^{6}$ In our study, no differences concerning symptoms which included acid reflux and dysphagia were determined between the patient and control groups, which could be related to the low number of patients. On 
the other hand, in the mentioned study only symptoms were questioned and no other method was used for comparisons. Yet in our study, all types of reflux were evaluated with impedance-pH metry. In our study although alkaline reflux after cholecystectomy decreased and reflux transformed into a more acidic $\mathrm{pH}$, no statistical differences were determined concerning the impedance $\mathrm{pH}$ results between the patient and control groups. Participants who did not have symptoms and had similar weights as the cholecystolithiasis patients were selected, as much as possible, for the control group. Since the pre and post operative reflux signs did not differ significantly among the cholecystolithiasis cases, it was considered that cholecystectomy did not result in serious reflux problems.

The pathophysiological effect of regurgitation of duodenal content into the esophagus is controversial in GER disease. In a study of 52 cases and 43 controls where the ambulatory esophageal aspirate was evaluated and the findings were correlated with a 24-hour $\mathrm{pH}$ monitoring, it was determined that the rate of acid concentrations was higher among the GER patients compared to the control group $(P<0.010)$. A significant correlation $(P<$ $0.010)$ was determined between the bile acid concentration and the $\mathrm{pH}$ being above 7 , which was strongest at nights $(\mathrm{r}=0.59, P$ $=0.006)$. This correlation was also determined in patients who had stricture and Barrett's esophagus $(P<0.010)$. With these findings, it was interpreted that contaminated gastric fluid predisposed to stricture and Barrett's esophagus formation and $\mathrm{pH}$ being above 7 indicated bile reflux. ${ }^{8}$ Our study determined that gallbladder stones increased the weakly alkaline reflux, whereas after cholecystectomy the alkaline reflux decreased and the acid reflux increased.

Until now, the relationship between gallbladder stones, cholecystectomy and GER was evaluated with esophageal $\mathrm{pH}$-metry. In order to detect the alkaline reflux, evaluation was carried out by gastric bilirubin monitoring. ${ }^{5,8}$ As far as we know, our study is the first one which examines these issues with impedance-pH metry.

Since alkaline reflux was higher among patients who had gallbladder stones compared to the controls, and alkaline reflux decreased while acid reflux increased after cholecystectomy, it was considered that additional factors might accompany cholecystectomy and cholecystolithiasis in GER pathophysiology. After cholecystectomy, due to the lack of bile reservoir, the bile flowing to duodenum changes and bile reflux to the stomach increases. Due to the changes in neurohumoral axis, the upper gastrointestinal motility might change. This might cause GER and duodenogastric reflux. ${ }^{8}$ Similar changes might also occur in the presence of gallbladder stones. More comprehensive studies with larger number of patients and controls and evaluations on other causal factors (diet, functional disorders, lower esophageal pressure changes and neurohormonal changes etc) could provide more informative results in explaining the reflux pathogenesis.

The lack of correlation among the impedance-pH metry results and the symptom scores might be due to the low number of patients and controls. Decrease of the weakly alkaline reflux and increase of acid and gas reflux which were determined with impedance-pH metry did not cause decrease or increase in clinical symptoms. It was probably derived from the values which were in the physiological limits.

Although the rate of persistent abdominal pain and nausea-vomiting named postcholecystectomy syndrome was determined as $2.6 \%-47.0 \%$, there were studies reporting that the symptoms after cholecystectomy did not increase and the symptoms that emerged might be associated with coexisting GER, irritable bowel disease, chronic pancreatitis, peptic ulcer or cholecystolithiasis. ${ }^{8}$

According to the results of our study, gastoesophageal weakly alkaline reflux develops among patients with cholecystolithiasis. It was also determined that, after the operation the gastroesophageal reflux transformed into a more acidic $\mathrm{pH}$ and gas reflux increased, while these changes did not differ from the control group and did not cause reflux symptoms.

\section{References}

1. Nakeeb A, Comuzzie AG, Martin L, et al. Gallstones: genetics versus environment. Ann Surg 2002;235:842-849.

2. Rothwell JF, Lawlor P, Byrne PJ, Walsh TN, Hennessy TP. Cholecystectomy induced gastroesophageal reflux: is it reduced by the laparoscopic approach? Am J Gastroenterol 1997;92:1351-1354.

3. Jazrawi S, Walsh TN, Byrne PJ, et al. Cholecystectomy and oesophageal reflux: a prospective evaluation. Br J Surg 1993;80:50-53.

4. Caldwell MT, Rothwell J, Lawlor P, et al. Oesophageal bile and acid reflux increases following cholecystectomy. Gastroenterology 1996;110: A449.

5. Manifold DK, Anggiansah A, Owen WJ. Effect of cholecystectomy on gastroesophageal and duodenogastric reflux. Am J Gastroenterol 2000;95:2746-2750.

6. McNamara DA, O'Donohoe MK, Horgan PG, Tanner WA, Keane FB. Symptoms of oesophageal reflux are more common following laparoscopic cholecystectomy than in a control population. Ir J Med Sci 1998;167:11-13.

7. Nudo R, Pasta V, Monti M, Vergine M, Picardi N. [Correlation between post-cholecystectomy syndrome and biliary reflux gastritis. Endoscopic study.] Ann Ital Chir 1989;60:291-300. [Italian] 
8. Stein HJ, Feussner H, Kauer W, DeMeester TR, Siewert JR. Alkaline gastroesophageal reflux: assessment by ambulatory esophageal aspiration and $\mathrm{pH}$ monitoring. Am J Surg 1994;167:163-168.

9. Kellosalo J, Alavaikko M, Laitinen S. Effect of biliary tract procedures on duodenogastric reflux and the gastric mucosa. Scand J Gastroenterol 1991;26:1272-1278.

10. Aydın S, Akın ML.,Karakaya M, et al. Alkaline reflux gastritis and problems of diagnosis. Çağdaş Cerrahi Dergisi 1997;11:36-39.

11. Warshaw AL. Bile gastritis without prior gastric surgery: contributing role of cholecystectomy. Am J surg 1979;137:527-531.

12. Kawaura Y, Tatsuzawa $\mathrm{Y}$, Wakabayashi T, Ikeda N, Matsuda M, Nishihara S. Immunohistochemical study of p53, c-erbB-2, and PCNA in Barrett's esophagus with dysplasia and adenocarcinoma arising from experimental acid or alkaline reflux model. J Gastroenterol 2001;36:595-600.

13. Scarpa PJ, Cappell MS, Chen WY, Liao WC. Treatment with ursodeoxycholic acid of biler reflux gastritis after cholecystektomy. J Clin Gastroenterol 1991;13:601-603.

14. DeVault KR, Castell DO. Updated guidelines for the diagnosis and treatment of gastroesophageal reflux disease. The practice parameters committee of the American College of Gastroenterology. Am J Gastroenterol 1999;94:1434-1442.

15. Zerbib F, Roman S, Ropert A, et al. Esophageal $\mathrm{pH}$-impedance monitoring and symptom analysis in GERD: a study in patients off and on therapy. Am J Gastroenterol 2006;101:1956-1963.

16. Bredenoord AJ, Tutuian R, Smout AJ, Castell DO. Technology review: Esophageal impedance monitoring. Am J Gastroenterol 2007; 102:187-194.
17. Silny J. Intraluminal multiple electric impedance procedure for measurement of gastrointestinal motility. Neurogastroenterol Motil 1991;3:151-162.

18. Sifrim D, Dupont L, Blondeau K, Zhang X, Tack J, Janssens J. Weakly acidic reflux in patients with chronic unexplained cough during 24 hour pressure, $\mathrm{pH}$ and impedance. Gut 2005;54:449-454.

19. Zerbib F, des Varannes SB, Roman S, et al. Normal values and day to day variability of 24 hours ambulatry impedance-pH monitoring in a Belgian-French cohort of healthy subjects. Aliment Pharmacol Ther 2005;22:1011-1021.

20. Koek GH, Sifrim D, Lerut T, Janssens J, Tack J. Effect of the $\mathrm{GABA}(\mathrm{B})$ agonist baclofen in patients with symptoms and duodeno-gastro-oesophageal reflux refractory to proton pump inhibitors. Gut 2003;52;1397-1402.

21. Richter JE. Severe reflux esophagitis. Gastrintest Endosc Clin North Am 1994;4:677-698.

22. Bor S, Vardar R, Vardar E, Takmaz S, Mungan Z. Endoscopic findings of gastroesophageal reflux disease in Turkey: Multicenter prospective study (Gorhen). Gastroenterology 2008;134(suppl 1):A600.

23. Vandeplas Y, Salvatore S, Vieira MC, Hauser B. Will esophageal impedance replace $\mathrm{pH}$ monitoring? Pediatrics 2007;119:118-122.

24. Valipour A, Makker HK, Hardy R, Emegbo S, Spiro SG. Symptomatic gastroesophageal reflux in subjects with a breathing sleep disorder. Chest 2002;121:1748-1753.

25. Kim HN, Vorona RD, Winn MP, Doviak M, Johnson DA, Ware JC. Symptoms of gastroesophageal reflux disease and the severity of obstructive sleep apnea syndrome are not related in sleep disorders center patients. Alimant Parmacol Ther 2005;21:1127-1133. 